\title{
The Re-examination of Adjustment of the Rotor Magnetic Field Observer in the Induction Motor
}

\author{
Alexander Burkov (Leading Researcher, Ivanovo Power State University - ISPU), \\ Evgenii Krasilnikyants (Leading Researcher, ISPU), Alexander Smirnov (Doctoral Student, ISPU), \\ Georgy Bouldukan (Engineer, ISPU)
}

\begin{abstract}
Wide use of induction motor drives makes the problems related to induction motors very topical. One of such problems is the maximal utilization of torque and velocity of induction motors. In this regard the use and accurate adjustment of rotor magnetic flux observers may be helpful. The technique of observer adjustment is subject of special interest. This technique can be regarded as optimal if it ensures constant acceleration that, in turn, corresponds to constant magnitude of active and magnetizing components of stator current. In contrast, nonoptimal tuning of the magnetic flux observer creates a transient response caused by variation of magnetic and active components of the stator current resulting in changing acceleration of the motor. However, the parameters of non-optimal process can be used for fine tuning of the observer which considers the variation of the time constants obtained analyzing the drive's magnetic circuit saturation. It is possible to conclude that implementation of fine adjustment of rotor magnetic flux observer is of critical importance for induction motor torque and velocity maximum utilization.
\end{abstract}

Key words - Variable speed drives, motor drives, induction motors, optimal control, observers.

\section{INTRODUCTION}

Induction motors with squirrel-cage rotors are generally used in the industry nowadays. Their advantages are low cost, high maintainability, durability and overload capability. The optimal induction motor control can be obtained when torque vector control system is used. The distinctive feature of such controlling system is the occurrence of the rotor magnetic field observer for phase coordinates transformation determination [1-3]. There are different structures of observers that can be divided into two groups. The first group consists of the observers, which use the information about stator line currents and rotor position or velocity [4-7]. The second group consists of the observers functioning according to the data from current and voltage sensing devices [8-11]. Tentatively, controlling systems with such observers are called "sensorless", indicating the absence of the measuring element on the motor shaft.

The application of the first group observers is preferred more in the cases when the dominant requirement is the support of fast response in torque loop and wide range of regulation. The observers from the second group support considerably smaller range of regulation and weaker performance of torque loop, but allow diminishing the cost of the electric motor drive.

Apart from the types of the used observers, to ensure the integrity of the controlling system requires the estimation of motor parameters including those the direct determination of which is difficult or impossible. They are rotor characteristic time $\operatorname{Tr}$ and stator-rotor mutual inductance $L_{12}$. It should be noted that these parameters are subjected to great variance depending on nonlinearity of the magnetization curve and temperature [2]. As a result, the observer parameters should be corrected depending on external factors.

\section{GENERAL DESCRIPTION OF THE INDUCTION MOTOR PARAMETERS IDENTIFICATION METHODS}

Literature review proved that great attention is paid to the problem of identification of the parameters of the induction motors with squirrel-cage rotor [11-19]. The concerned methods of identification can be divided into two groups. The first group consists of the methods that consider parameter identification when electric motor drive is put into operation. For this purpose the application of the set of different testing modes are suggested, for example, no-load run, short circuit, the formation of zero and synchronous speed or the development of the transient process, for example, stepped frequency variation $[11,12]$. The second group consists of the methods, which are headed for motor parameter on-line estimation. Thereby, it is suggested to add test signal into the actuating signal. The test signal is insignificant in comparison with the original drive signal.

Genetic algorithms, use of fuzzy logic or frequency analysis is suggested to be used for processing of experimental results in automatic mode [13], [17-19], [14]. It should be noted that the application of complicated calculations and test signals, which differ greatly from ones used during drive operational process, is difficult to put into practice during manufacturing conditions.

Among analyzed induction motor parameters identification methods the ones suggested in [11], [14] are better suited for practical application. The method, described in [14], allows defining the parameters of induction motor T-equivalent circuit. Thereby, stator active resistance is measured at stator direct voltage, but other parameters - at the modes of no-load run and short circuit. Current meter, electric power meter and voltage meter is necessary for data acquisition.

The approach, stated in [11], assumes the use of four test modes: fluctuating vector (bogey values of magnitude and angular location are constant), no-load running, short circuit (lay shaft is stationary, voltage vector rotates with some frequency) and motor cut-off from electric power supply. 


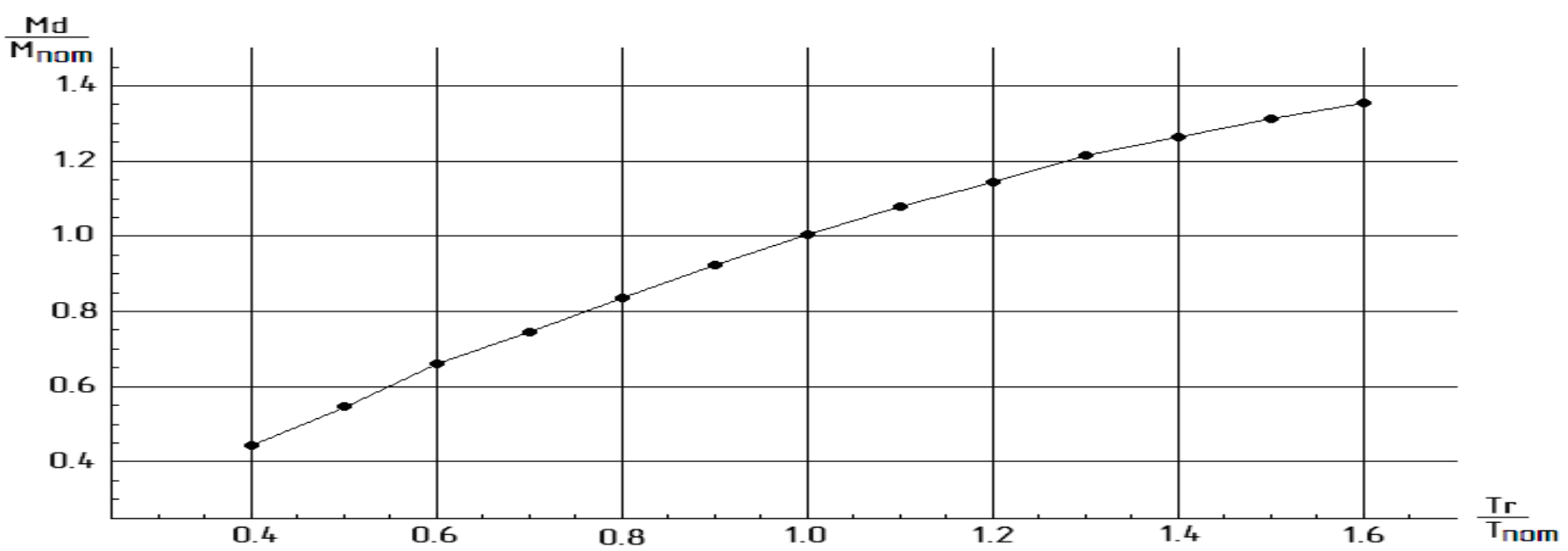

Fig. 1. The characteristic curve of the torque according to the Tr valuation inclination.

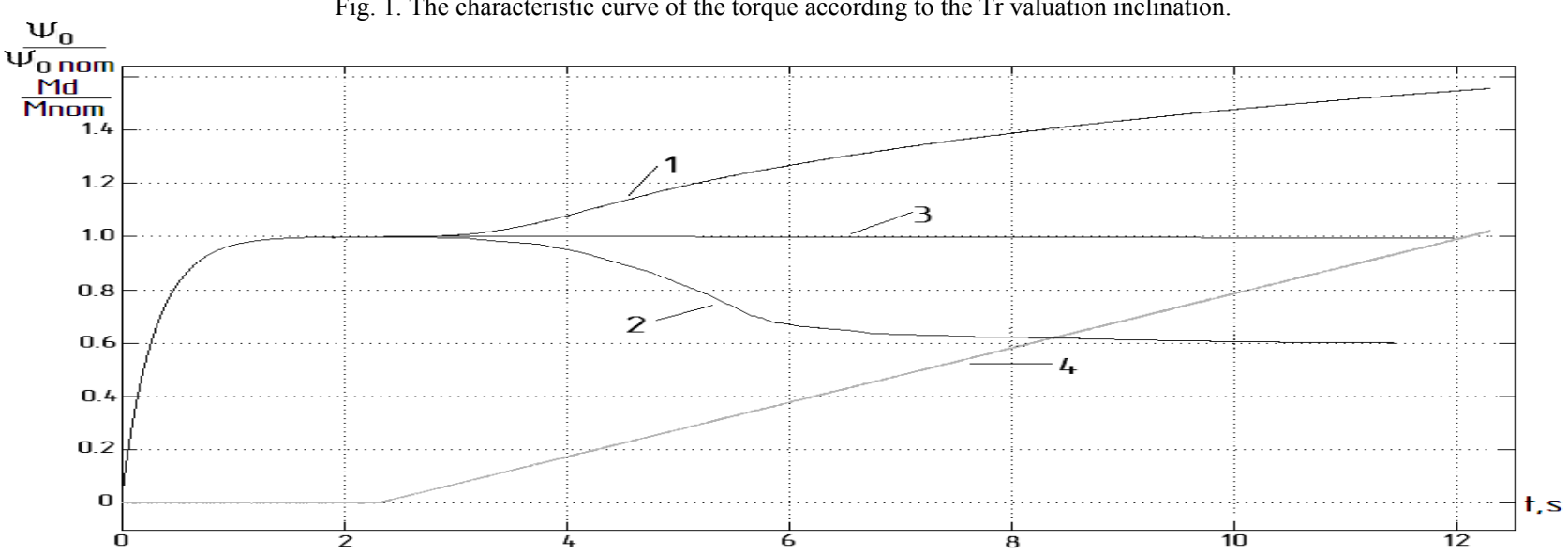

Fig. 2. The transient of the magnetic flow during the load torque increase: curve $1-\operatorname{Tr} / \operatorname{Tn}=1.4$; curve $2-\operatorname{Tr} / \operatorname{Tn}=0.6$; curve $3-\operatorname{Tr} / \operatorname{Tn}=1$; curve $4-$ load torque.

In the context of the given approach all of the motor parameters are determined consequently. For calculations the data of phase currents and voltages, measured in the drive, are used. It allows avoiding the use of additional measurement devices. Each parameter has its own criterion of adjustment accuracy. However these approaches, in spite of the relative simplicity, have a number of disadvantages. The first method allows determining the parameters only for the static mode of operation. It complicates the parameter change depending on nonlinearity of the magnetization curve, temperature and other external factors. The second method requires experienced personnel to realize complicated computations and it also requires considerable time span. It should be noted that in both cases the determination of the parameters of the drive equivalent network is carried out. These parameters are not used directly, but in each specific system their additional recalculation, which takes into account the scaling coefficients, is required.

In summary, in conditions when modern induction motor drives with vector controlling system are used, the up-to-date problem is the development of the method for adjustment of the rotor magnetic flow observer that provides the maximum utility of the induction drive according to the torque and velocity usage. Such a method should be noted for its simplicity, small amount of calculations and should be performed according to the adjustment factor of quality. It should be universal concerning the structure of the observer.
This paper presents a development of an adjustment technology for the rotor magnetic field observer in the induction motor suitable for industrial applications.

\section{THE RESEARCH OF THE IMPRECISION INFLUENCE IN ROTOR CHARACTERISTIC TIME ESTIMATION ON THE SYSTEM CHARACTERISTICS}

For determination of the imprecision influence in rotor characteristic time value $T r$ on the system characteristics the investigation of the mathematical model of the vector torque loop was carried out in Simulink. During the experiments the pattern of the electric drive functioned in position hold-up mode. The valuation of $T r$, used in the structure of the rotor stream phase observer, changed within the range from 0.4 to 1.6 of the rotor characteristic time bogey value in increments of 0.1. For each $T r$ value the motor torque was defined at stator current bogey value. The results of the simulation for motor with the power of $15 \mathrm{~kW}$ are shown in Fig.1.

The given characteristic curve shows that rotor stream phase observer alignment error greatly affects the torque value, gained by the motor at the same stator current and primary voltage. According to the analysis results, the $\mathrm{Tr}$ valuation inclination within the range from $-10 \%$ to $+10 \%$ of the bogey value, the torque affect of the introduced error is insignificant, which is $\pm 7-8 \%$. At the $\operatorname{Tr}$ valuation inclination of about $60 \%$ or more, the inclination of the torque at the given stator current value can increase by up to $40-50 \%$. 


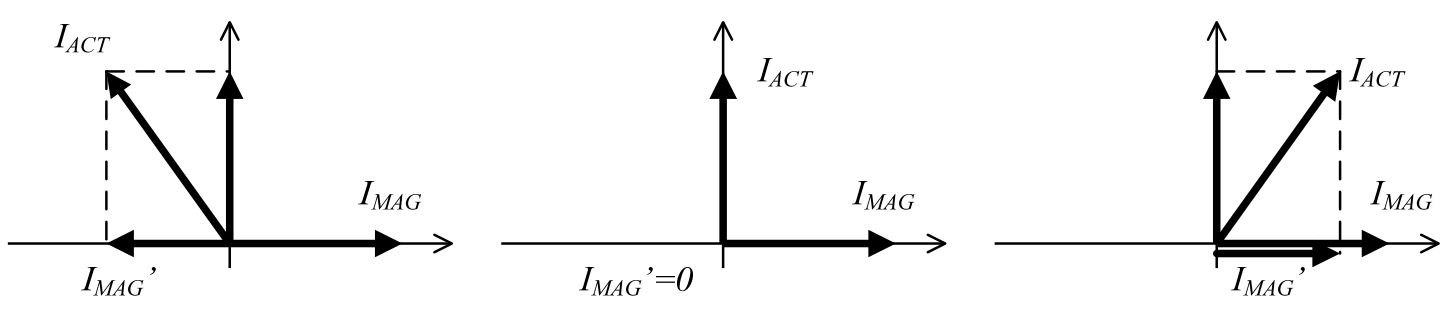

Fig.3. Vector diagrams of the orientation of the real stator current component.

The reason of the dependence of the induction motor torque from the $T r$ valuation inclination is the presence of the cross coupling between magnetizing and active stator current components. When the $\operatorname{Tr}$ valuation corresponds to the real value of the rotor characteristic time Tnom then the active component slightly influences the motor magnetic field. Thereby the currents turn out to be on parallel axes of the system of reference. In the case of the wrong adjustment, stator current component, formed in the torque control channel, turns out to be reclining to the magnetic flow and magnetizing current. In this case the active current either partly demagnetizes or magnetizes the motor, in other words forms a parasitic magnetizing current, which increases as the motor load increases (Fig.2).

On the basis of the obtained results it is possible to make a conclusion that even when the deviation of the rotor characteristic time valuation from the real value is significant (up to 50-60\%), the system keeps its operating capability, but hereby from the power point of view it becomes inefficient. So, in the absence of the severe requirements to the drive energy efficiency the characteristic time valuation is possible with an accuracy of 20-30\%. However, in cases, when any loss of the torque or velocity is unacceptable, the definition of the characteristic time precise value is a necessary condition to guarantee the wish-list capabilities of the electric drive. Main motion drives of a cutting machine, operating in the zone of deep field weakening, can be the examples. In this situation in the case of a great demagnetizing the motor turns out to be incapable to provide the torque requirement due to the limitation on stator current absolute value. On the other hand, when there is a strong magnetizing, the increase of the motor magnetic constant, and as a consequence back electromotive force results in speed range reduction. According to these facts, for more complete resource management of the induction motor with vector control it is necessary to exploit a method of $T r$ parameter selection and adjustment.

It should be noted that according to the authors' experience, the variation of rotor characteristic time of the induction motor of general industrial version of the same unit size, for different manufacturers, can reach up to $30 \%$. The motors of the same manufacturer and unit size can have the parameter variation up to $7-10 \%$. As a result, if one does not specify strict requirements to the electric drive characteristics, it is possible to use averaged values to valuate $T r$. If it is necessary to guarantee the minimum torque loss rate, then it is necessary to make the $\operatorname{Tr}$ valuation for every induction motor.
So far, there are some conclusions:

1) the error of estimation of rotor characteristic time defines the angle included between the calculated and the active stator current components, formed by the channels of the magnetic flow and torque, or, in other words, the degree of the cross coupling between the control channels;

2) in the case of inaccurate observer adjustment the occurrence of the action current (when speedup or slowdown and the external torque application take place) will result in the motor demagnetization or magnetization (Fig.3), and as a consequence will change the motor torque and its magnetic constant.

Based on these statements, it is possible to estimate the value of cross coupling between the channels of the active and magnetic current component by the magnetic flux measurement and induction motor torque. Considering that the direct magnetic flow determination is difficult, we will use the induction motor torque value for $\operatorname{Tr}$ parameter estimation.

The induction motor torque correspondence with the active and magnetizing currents is described by the formula:

$$
M_{D}=C_{M}\left(I_{M A G}\right) \cdot I_{M A G} \cdot I_{A C T},
$$

where $M_{D}$-motor torque, $C_{M}\left(I_{M A G}\right)$ - magnetic constant as a function of magnetizing current, $I_{M A G}$ and $I_{A C T}$ - magnetizing and active stator current components.

In general case the dependence of motor torque from magnetizing current is nonlinear due to motor magnetic circuit saturation. Consequently, the mentioned effect must be borne in mind for a neat description of induction motor. Particularly it is done by introduction of coefficient $\mathrm{C}_{M}\left(\mathrm{I}_{M}\right)$ in equation (1). This coefficient takes into account the mutual inductance variation due to saturation magnetic circuit and design features of a certain motor.

However, the given formula is the mathematical description of the fact that when the magnetizing current, apart from nonlinearity of the magnetization curve, velocity, time and environments, is constant in the linear zone, the motor torque must be a linear function with a specification of the active current:

$$
M_{D}=\text { const } \cdot I_{A C T} \text {. }
$$

In the vector drive control system when there is a closedloop regulation system of the position or velocity, the use of the equation (2) for the adjustment is difficult due to the interrelation between the active and magnetizing components of the stator current. That is why the flow observer adjustment 
should be performed with a disconnected outer loop. At such approach, as it follows from the formula (2), the induction motor torque can be used as the valuation of the cross coupling:

$$
M_{D}(t) \approx \text { const } .
$$

The direct application of the formula (3) in adjustment process requires explicit evaluation of the induction motor torque. In some publications it is pointed out that it is possible to indirectly estimate the torque by stator current components generated by the motor in the vector controlling system. However, as the examinations showed, the given predicate, applied to induction motors, is true only for a well adjusted rotor magnetic flow phase observer. A direct measurement of the torque by means of a loading machine is expensive, because it requires special equipment.

On the basis of disadvantages of the discussed torque definition methods, as well as the chosen test action, it is suggested to use rotor acceleration as the valuation of the dynamic motor torque:

$$
M_{D}=\varepsilon \cdot J_{P}+M_{C},
$$

where $\varepsilon$ - motor acceleration, $J_{P}$ - rotor moment of inertia, $M c$ - load torque.

Rotor acceleration can be rather easily obtained by the calculation of the second finite difference from the rotor position measuring instrument.

So, the basic criterion of the quality of the rotor flow observer adjustment is reputed to be the acceleration constancy, which is time independent and assigned to the active current, at the electric drive acceleration at no-load run.

\section{EXPERIMENTAL VERIFICATION}

As the testing showed, it is wiser to perform observer adjustment in several steps. The first step is the flat tuning; as a result the approximate evaluation of the rotor characteristic time for the rating value of magnetizing current is defined. The second step is the accurate adjustment, that allows to obtain the given quality criteria. If there is the necessity of the magnetic flow control, the third step is performed, where the offset calculation of the observer adjustment according to the value of the magnetizing current is carried out.
Before starting the adjustment, it is necessary to adjust the magnetizing current equal to the no-load motor current, so that the motor would be in a mode, close to the nominal one. The value of the no-load current can be measured at the induction motor direct connection to the three-phase network. An alternative way of the no-load current identification may be its calculation on the basis of the data of the effective stator current. For most motors the value of the no-load current is $30-40 \%$ of the given value.

At the first step of the flat tuning the experimentations are performed for the motor acceleration with a constant assignment on the active current, equal to $80-120 \%$ from the identified magnetizing current. The start $\operatorname{Tr}$ value is chosen to be large, that is about $10-15$ seconds. If the drive after the assignment injection on the active current starts rotating and stops or rotates at a constant speed, then it is necessary to diminish the characteristic time $T r$. The adjustment at this stage is reputed complete, when the drive steadily picks-up the speed until the occurrence of the voltage constraints.

During the step of the accurate adjustment in order to gain the characteristic time value $T r$, a series of experiments for speeding-up the electric drive with different values of active current assignments is performed. In real conditions it is sufficient to pick 4 - 5 active current discrete levels that cover all operative range. Theoretically the dependence of the electric drive acceleration from time must be linear, until the stator voltage constraints occurrence. In practice, the nature of the process according to the active current assignment can alter considerably as a result of the cross coupling influence. As a result of the acceleration process nature evaluation, it may be necessary to correct $T r$ either upwards, if the acceleration increases with velocity increase, or downwards, if the acceleration decreases with velocity increase. The adjustment process stops when there is an acceleration constancy assurance, and it is time-independent and active current assignment independent.

The developed adjustment technique of the characteristic time was checked experimentally on an electric drive prototype model IntDrive-Auto with an industrial induction motor AИР100L4 with a capacity of $4 \mathrm{~kW}$ [16]. The result curves are shown in fig. 4-6. The engine active current assignment signal varied within the limits from 0.31 to $6.2 \mathrm{~A}$ in increments of $0.31 \mathrm{~A}$ with a magnetizing current of $4.65 \mathrm{~A}$

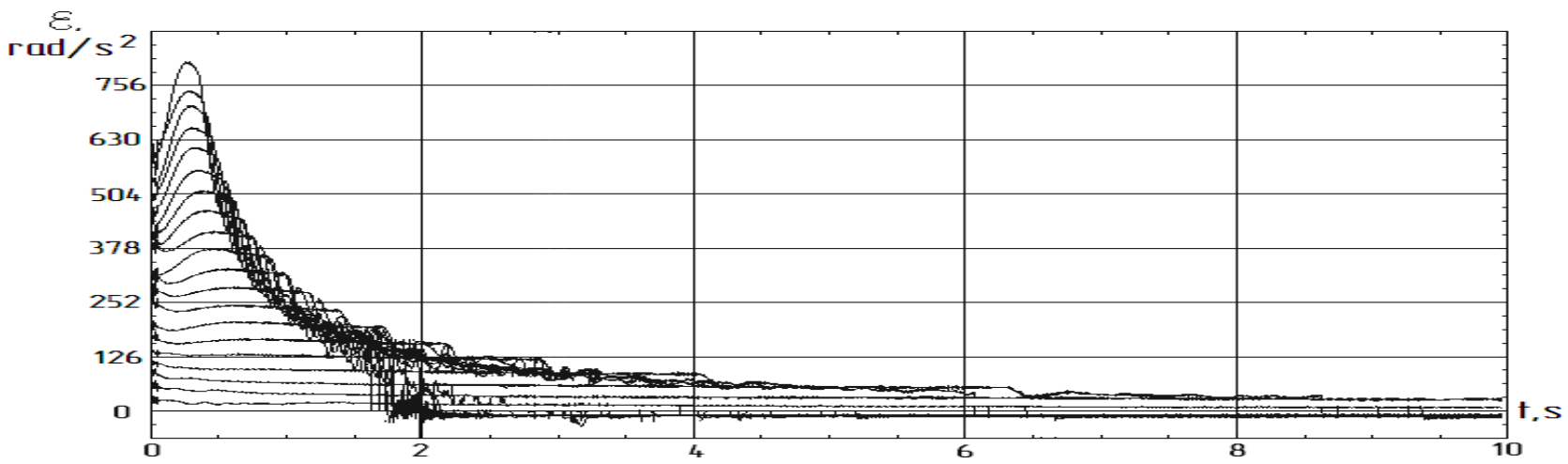

Fig. 4 The acceleration transient process at undervalue of $T r$. 


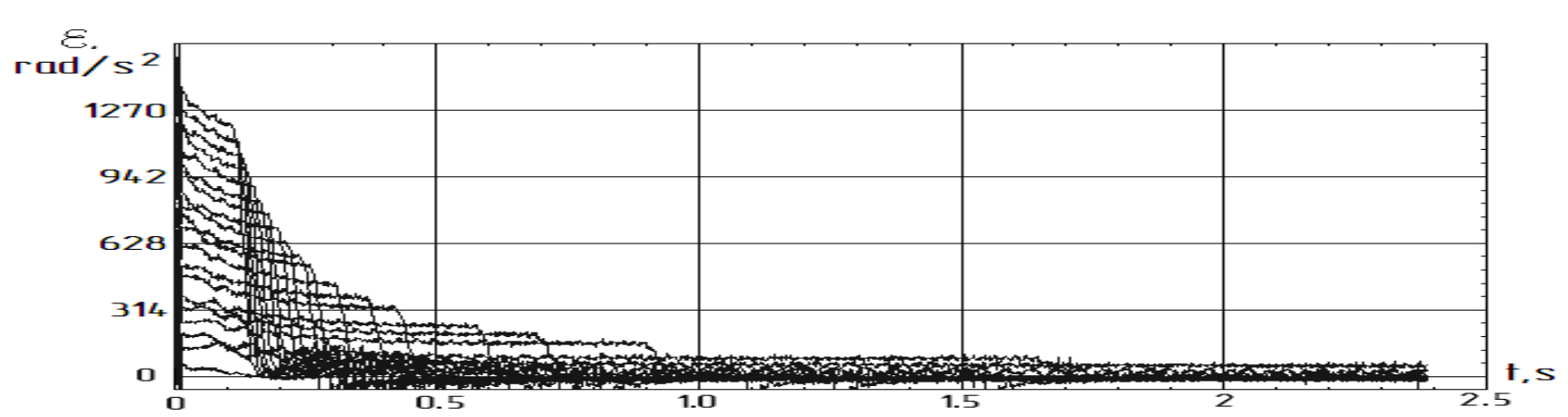

Fig. 5. The acceleration transient process at overvalue of $T r$.

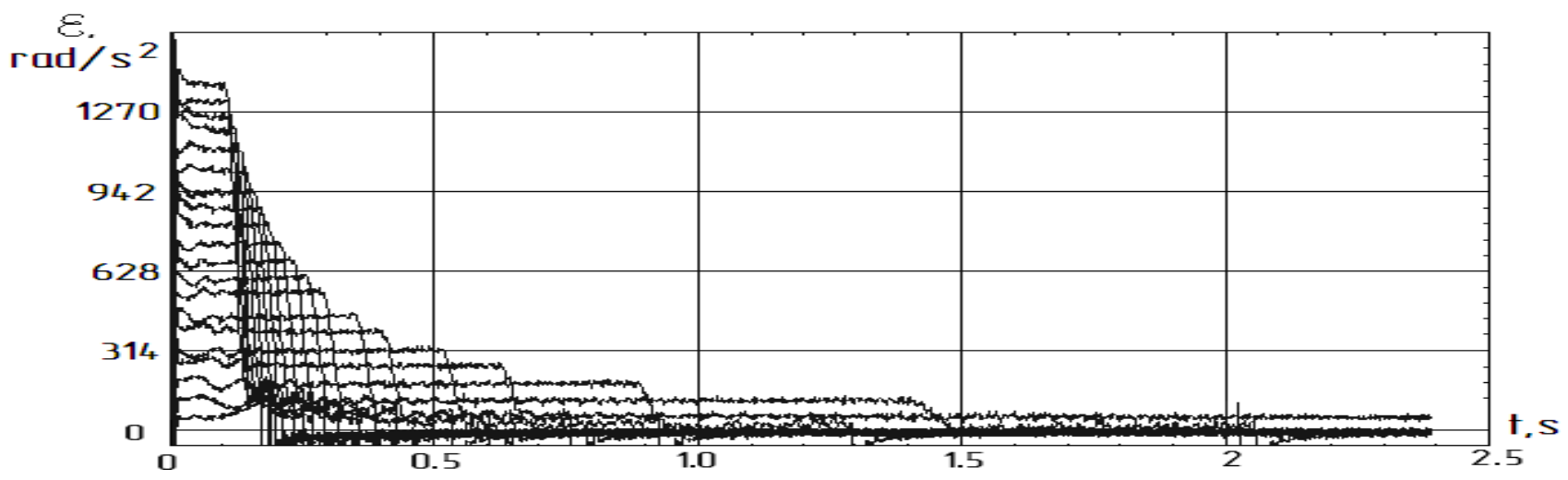

Fig. 6. The acceleration transient process at optimum estimation of $T r$.

In the case when the driver must operate with a constant magnetic flow, the observer adjustment can be considered to be complete. If magnetizing current control is intended, it is necessary to perform the third adjustment step.

The testing effect and the adjustment performance criterion used in the third step remain intact. The difference lies in the fact that in this case the variation incurs in the magnetizing current assignment and active current assignment for all the experiments stays constant. It is unreasonable to carry out the characteristic time adjustment for every magnetizing current value according to the method described earlier, because it requires a large number of experiments. That is why the characteristic time value $T r$ according to the magnetizing current may be determined numerically. The calculations are carried out on the basis of the data, gained from a number of experiments, that were accomplished with the rotor flow observer constant adjustment (Fig.7), taking into consideration a system of equations:

$$
\left\{\begin{array}{l}
\operatorname{Tr}=\frac{L_{P}}{R_{P}}=\frac{L_{2}{ }^{\top}+L_{12}}{R_{P}} \approx \frac{L_{12}}{R_{P}}=\frac{L_{12}\left(I_{M A G}\right)}{\text { constant }} \\
M_{D}=J \cdot \varepsilon=C_{1} \cdot I_{M A G} \cdot I_{A C T} \cdot L_{12}\left(I_{M A G}\right)
\end{array},\right.
$$

where $L_{P}, R_{P}$ - the deduced inductance and active resistance of the rotor phase, $L_{12}$ - the mutual stator to rotor inductance, $L_{2}$ ' - the self-inductance of the rotor phase dispersion, $C_{1}-$ coefficient characterizes the motor (number of poles pairs, etc).
Within the equation (5) there is an assumption that the selfinductance of the rotor phase dispersion L2 ${ }^{\prime}$ is negligible in comparison with the mutual inductance L12. This assumption is correct for most motors, because of L2' characterizes the part of motor magnetic flux, which is coupled only with rotor, while L12 characterizes the flux that threads both stator and rotor. The influence of the L2 'variation can be neglected.

Under the condition of assurance of the optimal adjustment if only for one value of the magnetizing current, using the equations of the system (5), the data on the actual value of the magnetizing current $I_{\mathrm{i}}$ and on the initial acceleration $\varepsilon_{i}$ at the given current, obtained from the graphs analysis (Fig.7), it is possible to make a formula for characteristic time recalculation for the specific magnetizing current value. For the magnetizing current, different from the bogey value, the recalculation equation is:

$$
\hat{\operatorname{Tr}}=\frac{\varepsilon_{i}}{\varepsilon_{\text {opt }}} \cdot \frac{I_{\text {opt }}}{I_{\mathrm{i}}} \operatorname{Tr}_{\text {opt }},
$$

where $\hat{\operatorname{Tr}}$ - design time constant, $\operatorname{Tr}_{\mathrm{opt}}$ - the characteristic time optimum value, $\varepsilon_{\text {opt }}-$ the acceleration, that corresponds to the optimum characteristic time value, $I_{\mathrm{opt}}$ - the magnetizing current, according to which the observer adjustment was carried out in the second step.

The developed correcting method according to the magnetizing current was checked on the driver experimental model. First, the experiments with the constant observer adjustment were carried out. The obtained curves are shown in Fig. 7. 


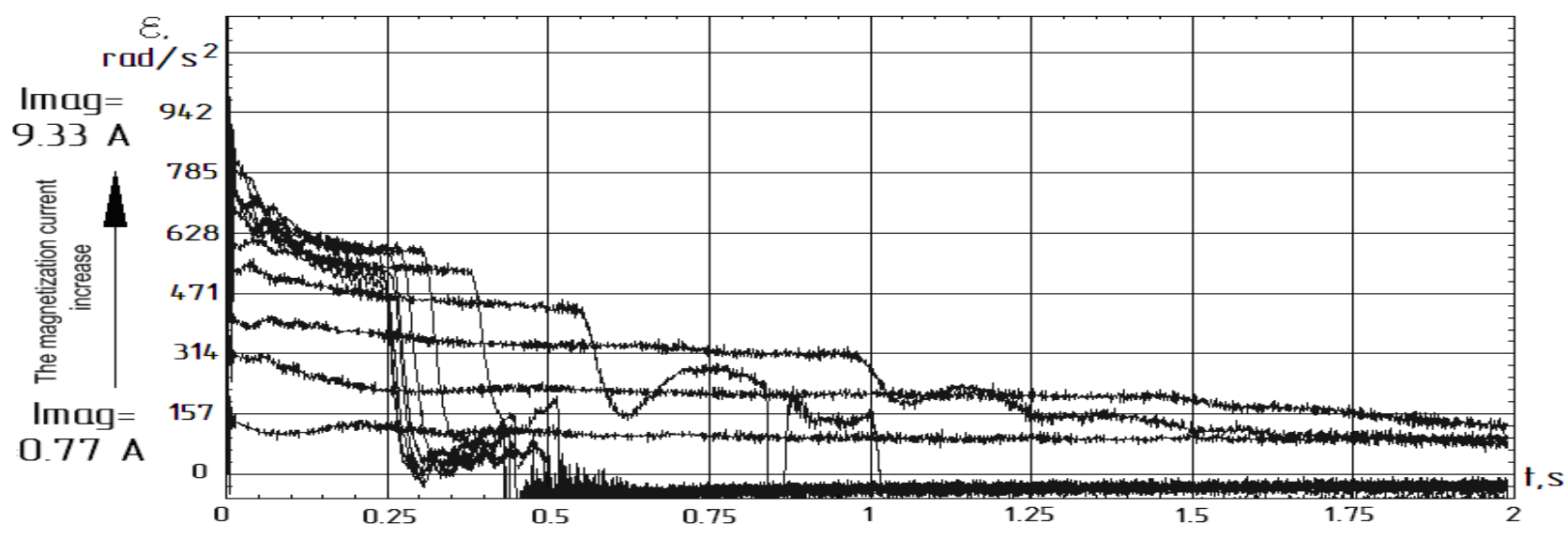

Fig. 7. The acceleration transient process at a constant observer adjustment.

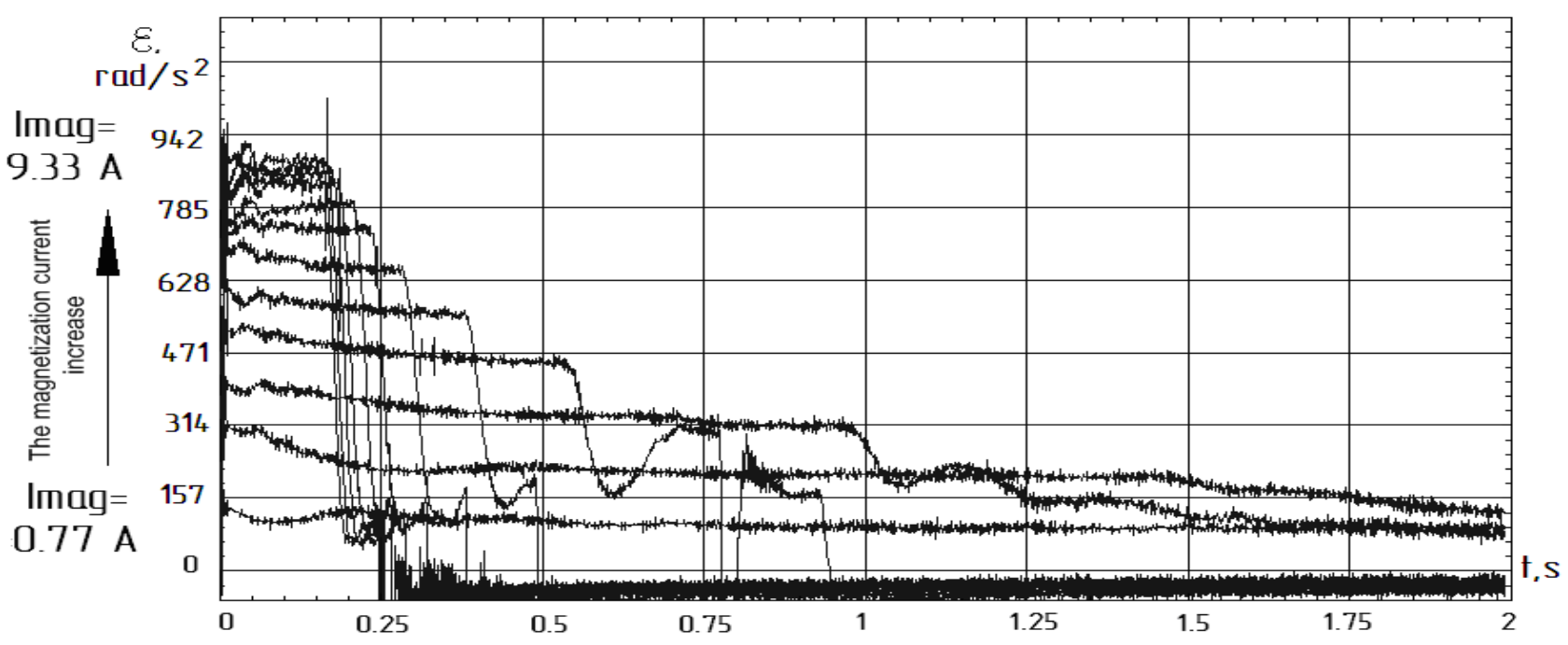

Fig. 8. The acceleration transient process at the observer adjustment correction.

The graph analysis shows that when the magnetizing current increases, the rotor flow observer adjustment progressively differs from the optimum. The obtained result is consistent with the system (5) and is explained by the dependence of the rotor characteristic time on the mutual inductance change when the operating point moves along the magnetization curve.

Then on the basis of the data on the initial acceleration values and the actual magnetizing current value, with the help of the equation (6) the calculation of the corrected values of the characteristic time was carried out. After that one more series of the experiments for the calculated characteristic time values were carried out. The results are shown in Fig. 8.

The analysis of the obtained results points out that the suggested algorithm of the rotor characteristic time correction allows to implement the suggested criterion of optimality (the acceleration value constancy during the progress of acceleration at the no-load run) during one series of experiments. Thereat, the developed method is simple enough and does not invoke special laboratory equipment.

\section{CONCLUSIONS}

In summary, it is possible to conclude, that in order to provide the maximum utility of the induction motor according to the torque and velocity, it is necessary to accomplish the accurate rotor magnetic flow observer adjustment. The method of the observer adjustment that uses the acceleration constancy at a constant value of the active and magnetizing stator current components is suggested. The main advantages of the described method are the lack of necessity of extra measuring devices and the prior data for the motor parameters. The chosen factor of adjustment quality is general and does not depend on the structure and specific model of rotor magnetic flow observer.

\section{ACKNOWLEDGEMENTS}

This research work was supported by the Russian Government by the state contract 13.G25.31.0057 «Development of high-speed, power efficient technological complex with digital control system for precision machining of parts of complicated configuration»». 


\section{REFERENCES}

[1] Peter Vas. Vector Control of AC Machines.// Clarendon Press, Oxford, United Kingdom, 1990.

[2] Felix Blaschke. The principle of field orientation as applied to the new transvektor closed-loop control system for rotating-field machines. //Siemens Review, 39(5):217-220, May 1972.

[3] Sakae Yamamura. Spiral Vector Theory of AC Circuits and Machines.// Clarendon Press, Oxford, United Kingdom, 1992.

[4] K. Ide, I. Murokita, M. Sawamura, M. Ohto, Y. Nose, J. I. Ha, and S. K. Sul, "Finite element analysis of sensorless induction machine by high frequency voltage," in Proc. Int. Power Electronics Conf. (IPEC), Tokyo, Japan, 2000, pp. 1842-1847

[5] G. Yang and T.-H. Chin, "Adaptive-speed identification scheme for a vector-controlled speed sensorless inverter-induction motor drive," IEEE Trans. Ind. Applicat., vol. 29, pp. 820-825, July/Aug. 1993.

[6] H. Hofmann and S. R. Sanders, "Speed-sensorless vector torque control of induction machines using a two-time-scale approach," IEEE Trans. Ind. Applicat., vol. 34, pp. 169-177, Jan./Feb. 1998.

[7] G. Guidi and H. Umida, "A novel stator resistance estimation method for speed-sensorless induction motor drives," IEEE Trans. Ind. Applicat., vol. 36, pp. 1619-1627, Nov./Dec. 2000

[8] Gnezdov, N., Kolganov, A. \& Lebedev, S. (2010). Application of astatic state observers in electromechanotronic modules. Proceedings of 51st International Scientific Conference of Riga Technical University, Section of Power and Electrical Engineering, pp. 151-154.

[9] Kolganov, A., Lebedev, S. \& Kulenko, M. (2013). Load Compensation in Mechatronic System with Observer. Electrical, Control and Communication Engineering, 1(1), pp. 5-45. Retrieved 16 Dec. 2013, from doi: 10.2478/v10314-012-0006-z

[10] Burkov, A., Krasilnikyants, E. \& Smirnov, A. (2011). The Model of Nonstationary Rotor Magnetic Field Observer in the Induction Motor. Proceedings of 52st International Scientific Conference of Riga Technical University, Section of Power and Electrical Engineering, pp. $137-142$.

[11] Vinogradov A.B., Chistoserdov V.L., Sibirtsev A.N. Self-adapting Vector Control System for the induction motor drive // Electrotechnics. 2003. №7.

[12] Identification of Induction Motor Parameters from Transient Stator Current Measurement. Steven R.Shaw, Student Member, IEEE, and Steven B. Leeb, Member, IEEE. Transactions on Industrial Electronics, VOL. 46, NO. 1, February 1999.

[13] Application of Genetic Algorithms to Motor Parameter Determination for Transient Torque Calculations. Pragasen Pillay, Senior Member, IEEE, Ray Nolan, and Towhidul Haque. IEEE Transactions on Industry Applications, VOL. 33, NO. 5, Sept./Oct. 1997

[14] Induction Motor Test (No-Load Test, Blocked Rotor Test): http://www.ece.msstate.edu/ donohoe/ece3414induction_machines_II.p df

[15] Investigation of induction motor parameter identification using particle swarm optimization-based RBF neural network (PSO-RBFNN). Hassan Farhan Rashag, S.P.Koh, S.K.Tiong, K.H.Chong and Ahmed N. Abdalla. Intarnational Journal of the Physical Sciences Vol. 6 (19), pp.4564-4570, September 2011.

[16] Researches of the Feeding Electric Motor Drive for NC Machines Burkov A.P., Krasilnikyants E. V., Smirnov A.A., Salahutdinov N.V. // ISPU Mercury - 2011.-№2, P - 71-77.

[17] J. M. Eguilaz, et al., "Induction motor optimum flux search algorithms with transient state loss minimization using fuzzy logic based supervisor," IEEE Conf. Proc. 1997, pp. 1302-1308.

[18] K. Sundareswaran, S. Palani, "Fuzzy logic approach for energy efficient voltage controlled induction motor drive, "IEEE Power Electronics and Drives Conf. Proc. PEDS 1999, pp. 552-554.

[19] G. C. D. Sousa, B. K. Bose, J. G. Cleland, "Fuzzy logic based on-line efficiency optimization control of an indirect vector controlled

[20] induction motor drive, ” IEEE Trans. Ind. Elec. Vol. 42, No. 2, 1995, pp. 192-198.
A. Burkov graduated from electro-mechanical faculty of Ivanovo Power Institute in 1975. Defended a master's dissertation in 1988 in Kostroma Institute of Technology. The topic of the dissertation was "The automatic control system of physical and mechanical parameters of fabric." Pursues a profession of a principal engineer in electronics and microprocessor systems department in ISPU. His research interests are power electronics in the power system, power quality, active power filters, renewable energy sources control, smart grids, and electrical vehicles.

Postal Address: Ivanovo State Power University, 34, Rabfakovskaya street, Ivanovo, 153003, Russian Federation.

E. Krasilnikyants graduated from electro-mechanical faculty of Ivanovo Power Institute in 1980. Defended a master's dissertation in 1989 in Ivanovo State Power University. The topic of the dissertation was "The controlling system of interrelated electric drive for in-line systems for manufacturing bonded fabrics". Pursues a profession of superior of a Training and Development Centre "NC and robot technology systems" in ISPU. His research interests are control systems for power electronic converters based on a wide range of algorithms, including modeling, design, and simulation.

Postal Address: Ivanovo State Power University, 34, Rabfakovskaya street, Ivanovo, 153003, Russian Federation.

A. Smirnov graduated from electro-mechanical faculty of Ivanovo State Power University in 2008. Defended a master's dissertation in 2011 in Ivanovo State Power University. The topic of the dissertation was "Development of digital induction electric drive for CNC machine tools". Pursues a profession of an assistant in electronics and microprocessor systems department in ISPU. His research interests include switch mode power converters, modeling and simulation of power systems, applied design of power converters and control systems and application, and development of energy storage systems.

Postal Address: Ivanovo State Power University, 34, Rabfakovskaya street, Ivanovo, 153003, Russian Federation.

G. Bouldukan graduated from electro-mechanical faculty of Ivanovo State Power University in 2003. Pursues a profession of an assistant in electronics and microprocessor systems department in ISPU. His research interests are in control systems for power electronic converters based on a wide range of algorithms, including modeling, design and simulation.

Postal Address: Ivanovo State Power University, 34, Rabfakovskaya street, Ivanovo, 153003, Russian Federation. 